\title{
The Study on Low Temperature Sintering of Nano-Tungsten Powders
}

\author{
Chai Ren, Z. Zak Fang*, Huan Zhang, Mark Koopman \\ Department of Metallurgical Engineering, University of Utah, 135 S. 1460 E. Rm 412, Salt Lake City, \\ UT84112, United States
}

\begin{abstract}
Ultrafine grain tungsten is a promising candidate for plasma facing component applications in future fusion reactors. The conventional press-and-sinter powder metallurgy method is a preferred route for producing ultrafine grain tungsten from nanosize tungsten powders. However, controlling grain growth, while simultaneously attempting to achieve maximum densification, has been a challenge for making UGF tungsten by sintering. In this study, the effect of processing parameters on the densification and grain growth of nano-W powders was investigated. Near-fully densified tungsten was obtained at sintering temperatures between 1100 and $1300{ }^{\circ} \mathrm{C}$, and both $\mathrm{Ar}$ and $\mathrm{H}_{2}$ sintering atmospheres were investigated. The Ar sintering atmosphere was determined to more favorably promote densification and minimize grain growth. The nanosized tungsten powder compacts were subjected to reduction in $\mathrm{H}_{2}$ as a part of the sintering cycle. The reduction temperature was found to have significant effects on the sintering of nano-W powder, primarily as a result of grain coarsening, which was seen at temperatures as low as $700{ }^{\circ} \mathrm{C}$.
\end{abstract}

Keywords: Nanocrystalline Material, Tungsten, Sintering, Grain Growth, Ultrafine grain

\section{Introduction}

Tungsten has a number of unique properties that establish it as a candidate material for fusion reactor applications. These properties include high melting point, high thermal conductivity, excellent mechanical properties at elevated temperatures, low tritium retention [1-2], low sputtering yield [3], and high erosion resistance [4]. These properties make tungsten especially promising for divertors and other plasma facing components in experimental fusion reactors, such as the International Thermonuclear Experimental Reactor (ITER) [5-6]. However, tungsten also has several serious deficiencies related to brittleness of the material, including room-temperature brittleness, recrystallization brittleness, and irradiation induced brittleness [7-9], which present risks in fusion reactor applications. The brittleness of tungsten may lead to poor thermal shock resistance when exposed to extremely high cyclic heating. And, additionally, brittleness also makes the material difficult to fabricate into functional components.

The use of nanocrystalline tungsten has been considered one of the approaches that could potentially improve the ductility of tungsten and decrease the ductile-to-brittle-transition-temperature DBTT [10]. The effect of the nanocrystalline structure or ultrafine grain structure on the mechanical behavior of tungsten has been shown by Y. Kitsunai et al. They showed that the DBTT can be reduced to $178.9^{\circ} \mathrm{C}$ for $\mathrm{W}$ alloys with an average grain size of $0.44 \mu \mathrm{m}[11]$. 
Similar effects of nanocrystalline structure have also been shown for other metals. Several research groups, that have investigated BCC metals such as Al and Mo, have proven that the high volume of grain boundaries from nanocrystalline structures modify the deformation mechanism, shifting it from intragranular dislocation activity to grain boundary rotation and sliding, which can significantly improve the ductility[12-13]. Based on simulation results of $\mathrm{Cu}$ and $\mathrm{Ni}$, nanocrystalline materials may also have improved irradiation resistance as the irradiation induced point defects can be absorbed by the larger grain boundary volume [14-15].

There are two main approaches to manufacture ultrafine grain tungsten: the top down approach, and the bottom up approach [16]. Severe plastic deformation (SPD) is an example of the top-down approach including several techniques, such as equal-channel angular processing (ECAP), high pressure torsion (HPT) and accumulative roll-bonding (ARB) [17-20]. The ultrafine grain tungsten materials prepared through these SPD based methods have shown improved strength and toughness, and decreased impurity concentrations [16, 21-22]. However, due to the nature of these SPD techniques, they are very difficult to scale up, and cannot be used to fabricate complex shapes with various geometries. The bottom-up approach involves the synthesis of nano-W powders, followed by a consolidation process, as in conventional powder metallurgy. The control of grain growth during the consolidation process is the most difficult challenge for this approach. A range of different consolidation processes such as hot isostatic pressing (HIP), spark plasma sintering (SPS), microwave sintering, and ultra-high-pressure rapid hot consolidation (UPRC) have all been applied to overcome this challenge [2327]. M. A. Monge et al. reported the preparation of pure tungsten samples consolidated by using HIP, and showed an average grain size of about $4.4 \mu \mathrm{m}$ with a relative density of about $92.7 \%$ [23]. Y. Kim et al. improved the relative density of pure tungsten to $96 \%$ using the SPS technique; however the average grain size in that study increased to $18.8 \mu \mathrm{m}$ [28]. Dispersing small amounts of thermally stable particles, like $\mathrm{La}_{2} \mathrm{O}_{3}, \mathrm{Y}_{2} \mathrm{O}_{3}$ and $\mathrm{TiC}$, into $\mathrm{W}$ has also been reported to inhibit grain boundary migration, and thus control grain growth during sintering [11, 28-30]. A study performed by Y. Kitsunai et al. showed the possibility of obtaining consolidated samples by HIPing at about $1950{ }^{\circ} \mathrm{C}$ with grain sizes as small as 50 $\mathrm{nm}$ by adding $0.5 \% \mathrm{TiC}$; however the maximum density was less than $94 \%$ [11]. Near fully dense tungsten with an average grain size of $2.0 \mu \mathrm{m}$ has been reported from work on consolidated W-4Ti samples by HIPing at $1700{ }^{\circ} \mathrm{C}$ [23]. However, the addition of $4 \mathrm{wt} . \%$ Ti reduced the theoretical density significantly from $19.25 \mathrm{~g} / \mathrm{cm}^{3}$ to only $17.02 \mathrm{~g} / \mathrm{cm}^{3}$. Clearly, the manufacturing of near fully dense tungsten material with high density and ultrafine grain size is still very challenging. Ultrafine grain size is defined here as grain sizes less than $500 \mathrm{~nm}$.

Others have predicted the difficulties of consolidating nano tungsten powders to achieve full density and ultrafine grain sizes, and proposed that ultrahigh compaction pressure and low sintering temperature are necessary [31-32]. In contrast, Wang et al showed that nano-W powders can be sintered to near-full density with pressureless sintering techniques at relatively low temperatures [33]. Another study showed the significant effect of green density on the densification behavior of nano-W powders [34]. However, detailed studies concerning the densification and grain growth during the pressureless sintering process of nano-W powder is still lacking.

In this work, a systematic investigation of the sintering of nano-sized ball milled tungsten powders using the low temperature pressureless sintering process was undertaken. The effect of processing parameters, including sintering temperature, atmosphere, and reduction temperatures, on the densification of nano-W powders is discussed. The objective of this research is to determine the best 
route by which tungsten can be sintered to near-full density with ultrafine grains by a conventional press-sinter method.

\section{Experimental Procedures}

The pure tungsten powders used as raw materials, with an average grain size about $50 \mathrm{~nm}$ and purity $>99.95 \%$, were supplied by Buffalo Tungsten Inc. These tungsten powders were mixed with heptane and ethanol and milled, using a custom designed high-energy planetary ball mill (HEPM) [35] for $6 \mathrm{~h}$. The milling process was performed in custom designed stainless steel canisters using $2 \mathrm{~mm}$ WC balls and a ball to powder ratio of 5:1. The acceleration field, nearly 60 times gravitational force, was generated by the combined revolution and rotation of mill canisters during milling, and effectively reduced the tungsten powders to nano-size. ICP and XPS chemical analysis were performed after milling and showed the contamination introduced during the milling process was negligible.

After milling, the tungsten powders were compacted into green parts using a uniaxial press. Powders were pressed into a cylindrical shape with $54 \mathrm{MPa}$ pressure. The green parts were approximately $16 \mathrm{~mm}$ in diameter and $4 \mathrm{~g}$ in weight. The green densities were calculated based on measurements of sample mass and dimensions, using the sample's cylindrical geometry. The average green density was about $6.55 \mathrm{~g} / \mathrm{cm}^{3}$ (34\% relative density). This relatively low green density is caused by the large friction force between nano-sized tungsten powders during compaction.

After compaction, the samples were reduced and sintered in an atmosphere controlled tube furnace at different temperatures with either $\mathrm{Ar}$ or $\mathrm{H}_{2}$ gas flow to study the effect of processing parameters on the densification behavior of the nano-W powders. Sintering experiments were carried out in two steps, a $700{ }^{\circ} \mathrm{C}$ reduction step in flowing $\mathrm{H}_{2}$ for $3 \mathrm{~h}$ and a 1000 to $1300{ }^{\circ} \mathrm{C}$ sintering step in either flowing $\mathrm{H}_{2}$ or Ar for $1 \mathrm{~h}$. Reduction experiments were performed with a 650 to $850{ }^{\circ} \mathrm{C}$ reduction step in flowing $\mathrm{H}_{2}$ for $3 \mathrm{~h}$ and a two stage sintering sequence of $1050{ }^{\circ} \mathrm{C}$ for $2 \mathrm{~h}$ and $1300{ }^{\circ} \mathrm{C}$ for $1 \mathrm{~h}$ in flowing Ar. Regular grade hydrogen and argon were used in this work with a hydrogen purity of $99.99 \%$ and argon purity of 99.998\%.

The average grain size of milled nano-W powders was calculated based on $\mathrm{x}$-ray diffraction (XRD) using the Williamson-Hall plot [36], and the densities of sintered samples were measured by the Archimedes method. The microstructures of nano-W powders and the fracture surfaces of sintered tungsten samples were characterized using an FEI NovaNano scanning electron microscopy (SEM). In order to measure grain size, the sintered samples were polished using Buehler MetaDi Supreme diamond suspensions and finished by polishing for 1 hour with 0.1 um diamond. SEM images with a strong backscattered component were taken on the polished surfaces, which revealed discernable grain orientation contrast, and the grain sizes were measured using the linear intercept method. At least 400 intercepts of grains were measured on randomly positioned lines on at least 5 randomly acquired SEM micrographs for each sample. The average grain size was calculated based on the lengths of these intercepts. The oxygen contents of sintered samples were characterized using a LECO TCH600 N/O/H determinator, and the Brunauer-Emmett-Teller (BET) method was utilized to calculate the specific surface area of as-reduced samples. 


\section{Results and Discussion}

\subsection{Characterizations of Milled nano-W Powders}

Figure 1 shows an SEM image of milled nano-W powders, after high-energy planetary milling. The milled powders show an irregular morphology with very fine particle size, approximately $50 \mathrm{~nm}$. These fine particles tend to agglomerate into larger particles with dimensions up to a few hundred nanometers. Figure 2 shows a comparison of XRD pattern of raw and milled nano-W powders. For both of the powders, only W peaks with Im-3m space groups can be observed in the XRD spectra. Milling for 6 hours led to a clear increase in the full width at half maximum of W XRD peaks. The average crystalline size of the milled nano-W was determined to be $16 \mathrm{~nm}$ based on XRD peak profiles, using the Williamson-Hall plot method [36]. Such a fine grain size is known to significantly improve the powder's sinterability and potentially reduce the required sintering temperature.

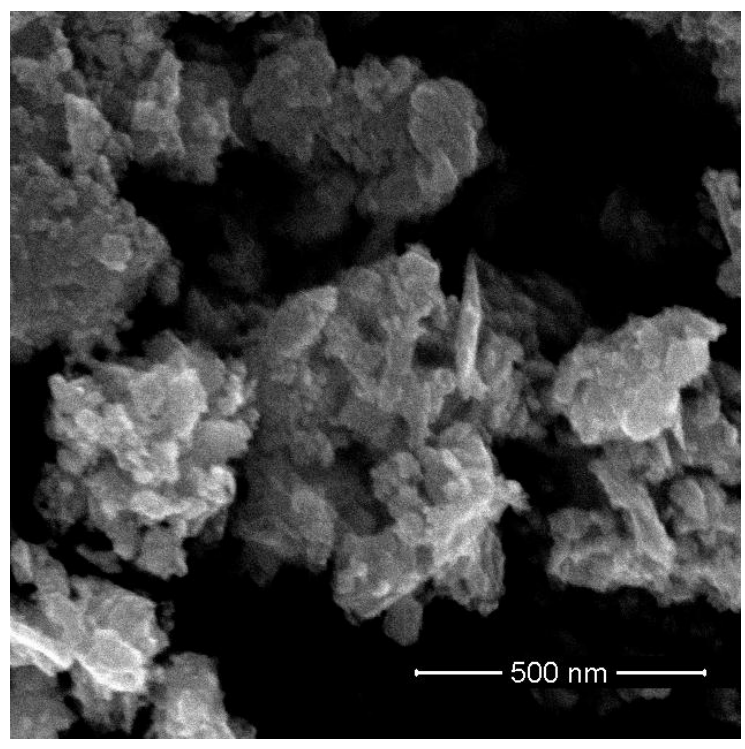

Figure 1 SEM image of the high energy planetary milled nano-crystalline $\mathrm{W}$ powders

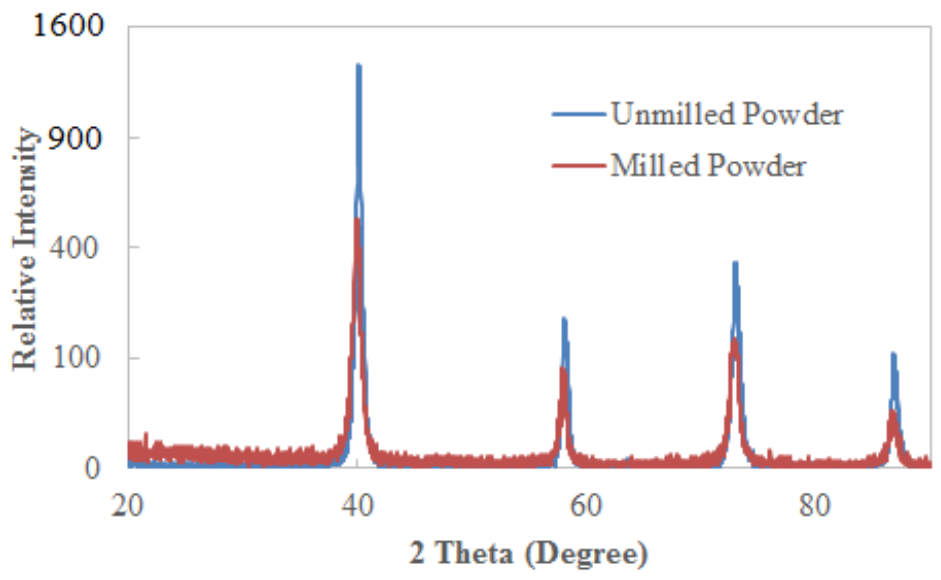

Figure 2 XRD pattern comparing raw and milled W powders.

3.2 Effect of Sintering Temperature and Atmosphere on Sintering of Nano-W Powders 
Figure 3 shows the evolution of densities as a function of sintering temperature with different atmospheres for the nano-W powders prepared using the HEPM process. Nano-W powders sintered in $\mathrm{H}_{2}$ atmosphere did not experience much densification after a $1 \mathrm{~h}$ holding time at 1000 or $1050{ }^{\circ} \mathrm{C}$, and only had moderate densification at temperatures up to $1200{ }^{\circ} \mathrm{C}$. Compared to the $\mathrm{H}_{2}$ atmosphere, W sintered in $\mathrm{Ar}$ had much better densification and reached a relatively higher density of $93 \%$ at temperatures as low as $1100{ }^{\circ} \mathrm{C}$. The highest density, $18.9 \mathrm{~g} / \mathrm{cm}^{3}$, was obtained at a sintering temperature of $1300^{\circ} \mathrm{C}$ with an $\mathrm{Ar}$ atmosphere. This corresponds to a relative density of $98.3 \%$ based on the tungsten theoretical density of $19.25 \mathrm{~g} / \mathrm{cm}^{3}$. The ability to obtain near-full density at 1200 to $1300{ }^{\circ} \mathrm{C}$ is a dramatic improvement compared to the 2000 to $2700{ }^{\circ} \mathrm{C}$ sintering temperatures used for commercial production. The use of a sintering process at atmospheric pressure also leads to a significant advantage in energy consumption and cost compared to the other more energy intensive approaches, like pressure-assisted sintering or rapid heating technologies. This low temperature sintering method is only achievable by the nano-sized tungsten powders, in this research produced using the HEPM process. The finer the tungsten powder, the better the sinterability and the more rapid the densification at a given temperature $[33,37]$.

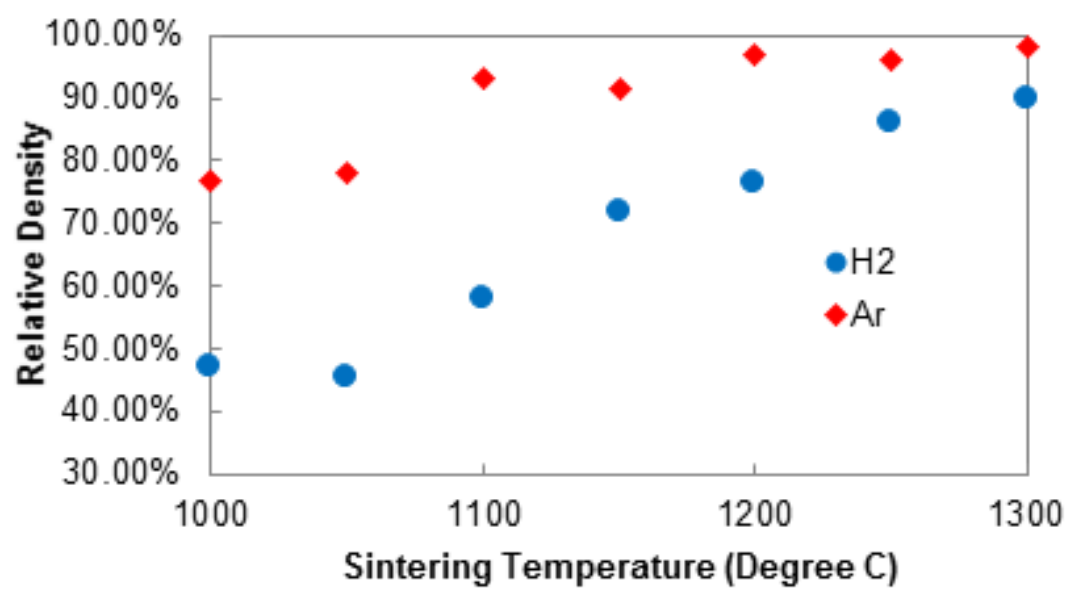

Figure 3 Effect of sintering temperature and atmosphere on the relative density of sintered nano-W powders.

For both types of atmosphere, the density of bulk tungsten increased with sintering temperature, which follows classic sintering theory. As the sintering temperature increases, the diffusion rate of atoms increases, which promotes densification kinetics [38]. Sintering in Ar led to better densification compared to sintering in $\mathrm{H}_{2}$, and the density difference between samples sintered in the two atmospheres was larger at lower temperatures and smaller at higher temperatures.

The sintering of $\mathrm{W}$ powders commonly takes place in three stages. The early stage involves neck formation and growth by diffusion with limited densification and an open pore structure. During the intermediate stage, the necks become blunted and the pore channels break up into small segments, essentially a transition from open porosity to closed porosity. The structure shifts to more rapid densification along with noticeable grain growth. In the final stage, pore segments become spherical isolated pores, the rate of densification decreases and grain coarsening becomes pronounced. Figure 4 shows SEM images of fracture surfaces of sintered W samples from different sintering temperatures and 
atmospheres. Tungsten powders sintered at 1000 and $1100{ }^{\circ} \mathrm{C}$ in $\mathrm{H}_{2}$, Fig. $4 \mathrm{a}$ and $4 \mathrm{~b}$, show microstructural features corresponding to the early stage, with necks forming between particles and high porosity. As the temperature increases to $1200{ }^{\circ} \mathrm{C}$ and above, Fig. $4 \mathrm{c}$ and $4 \mathrm{~d}$, the grains start to show polyhedral shapes, with less interconnected and more spherically shaped pores, which relate to the intermediate to final stages. This result is consistent with the results of density measurements from the sintered samples, which showed less than $58 \%$ density from samples sintered in hydrogen at $1100{ }^{\circ} \mathrm{C}$, while sintering above $1200{ }^{\circ} \mathrm{C}$ increased the density to above $76 \%$.

Compared to $\mathrm{H}_{2}$, sintering tungsten in Ar led to faster densification and a better polyhedral grain shape. The microstructure of the $1000^{\circ} \mathrm{C}$ sintered sample in Ar, Fig. 4e, already starts to exhibit blunted necks and segment shaped pores. The Ar sintered $\mathrm{W}$ reached the final stage at temperatures as low as $1100{ }^{\circ} \mathrm{C}$, Fig. $4 \mathrm{f}$, with fewer pores and higher density than the $1300{ }^{\circ} \mathrm{C} \mathrm{H}_{2}$ sintered sample. Rapid grain growth appeared as the sintering temperature was increased to $1200{ }^{\circ} \mathrm{C}$, Fig. $4 \mathrm{~g}$, which corresponds to the grain coarsening effect of the final stage.
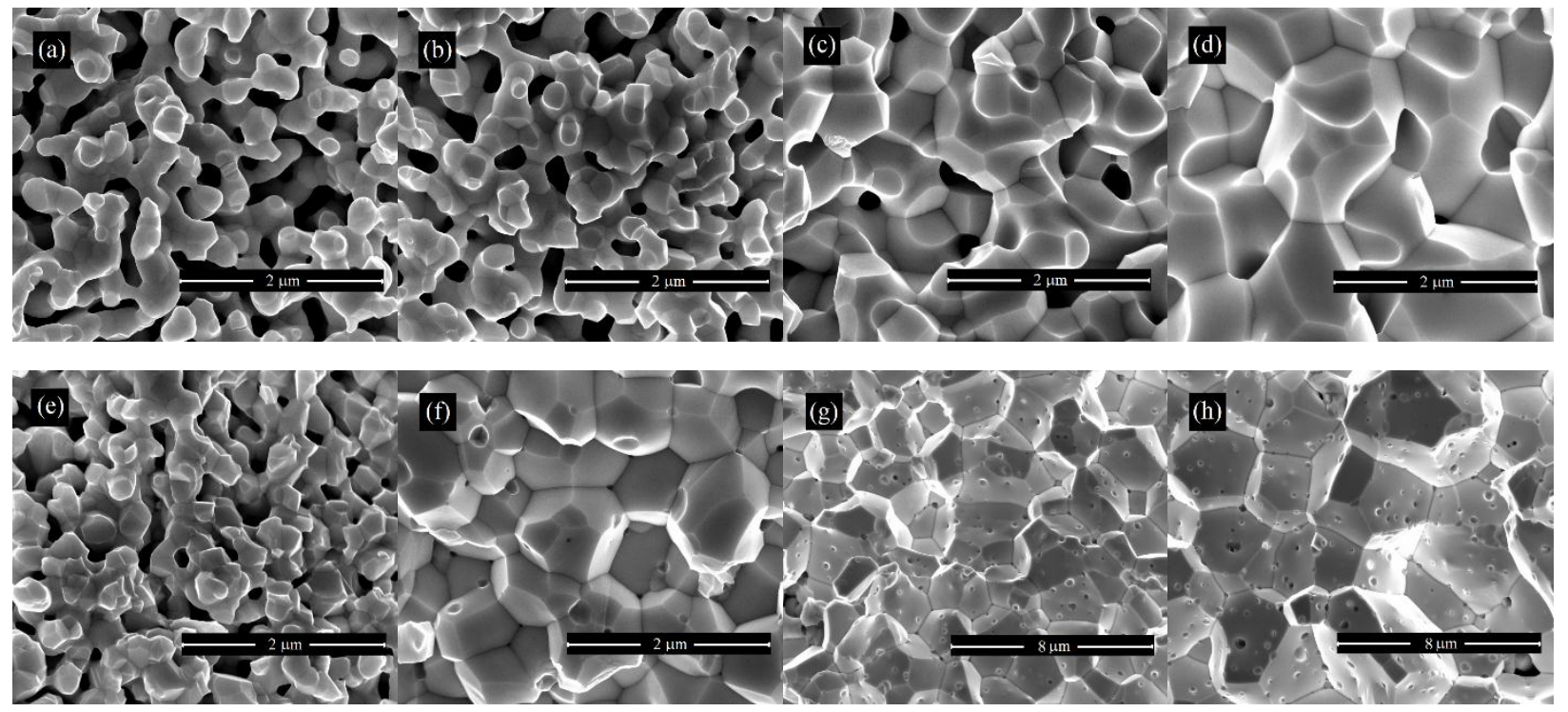

Figure 4 SEM fracture surface images of sintered nano-W at (a) $1000{ }^{\circ} \mathrm{C}$ in $\mathrm{H}_{2}$, (b) $1100{ }^{\circ} \mathrm{C}$ in $\mathrm{H}_{2}$, (c) $1200{ }^{\circ} \mathrm{C}$ in $\mathrm{H}_{2}$, (d) $1300{ }^{\circ} \mathrm{C}$ in $\mathrm{H}_{2}$, (e) $1000^{\circ} \mathrm{C}$ in $\mathrm{Ar}$, (f) $1100{ }^{\circ} \mathrm{C}$ in $\mathrm{Ar}$, (g) $1200^{\circ} \mathrm{C}$ in $\mathrm{Ar}$ and (h) $1300^{\circ} \mathrm{C}$ in $\mathrm{Ar}$.

Figure 5 shows the average grain size for the sintered nano-W powders, which were obtained from the analysis of SEM images taken of polished surfaces. Generally, the average grain size increases as the relative density and sintering temperature increase. The grain size of $\mathrm{H}_{2}$ sintered samples increases gradually and reaches a maximum of approximately $600 \mathrm{~nm}$ at $1300{ }^{\circ} \mathrm{C}$. The grain size of $\operatorname{Ar}$ sintered samples first increases slowly and then experienced rapid growth at temperatures higher than $1100{ }^{\circ} \mathrm{C}$ and relative density larger than $92 \%$. This is consistent with the SEM results above and was caused by grain growth during the final stage of sintering. At the same relative density, sintering in Ar leads to much finer grain size, as compared to sintering in $\mathrm{H}_{2}$. 


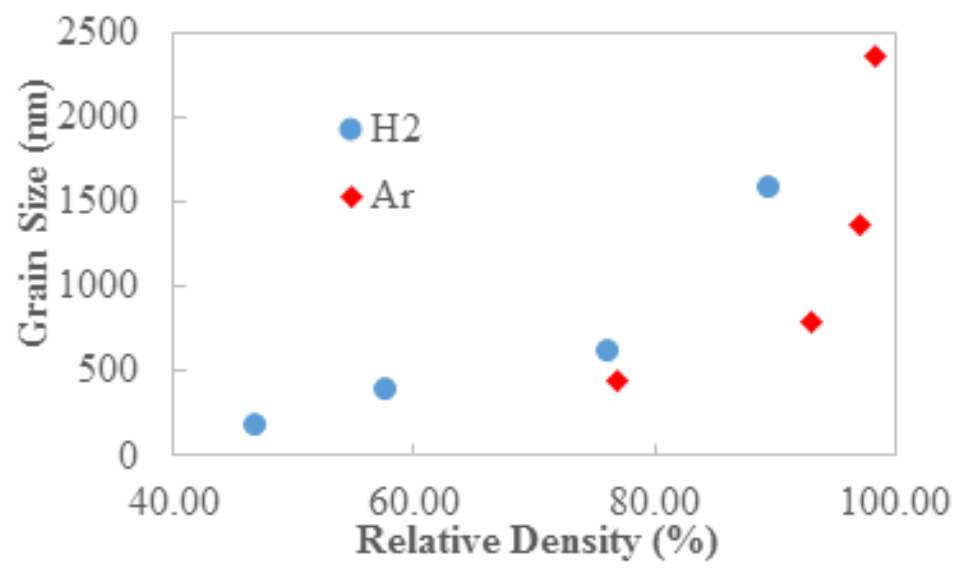

Figure $5 \mathrm{~W}$ grain size vs. relative sintered density of nano-W powders sintered at different temperatures and under different atmospheres.

Oxygen contents of the sintered samples were characterized using a LECO N/O/H determinator, and Fig. 6 shows the effect of sintering temperature on sample oxygen content. In an Ar atmosphere, oxygen content first decreases as the sintering temperature increases from 1000 to $1100{ }^{\circ} \mathrm{C}$, and then maintains a roughly stable value for samples sintered at temperatures up to $1300^{\circ} \mathrm{C}$. The drop in oxygen content with a sintering temperature increase from 1000 to $1100{ }^{\circ} \mathrm{C}$ was probably due to the removal of water vapor generated from reduction and the dissolved oxygen in the tungsten lattice. Any further decrease of oxygen would be impeded as the remaining oxygen was probably in the form of tungsten oxide, and an $\mathrm{Ar}$ atmosphere would not facilitate the reduction reaction. Compared to $\mathrm{Ar}$, oxygen content in samples sintered in a $\mathrm{H}_{2}$ atmosphere showed a constant decrease as the sintering temperature increased, and reached a very low level of $2 \mathrm{ppm}$ at $1300^{\circ} \mathrm{C}$. This indicates the continuous occurrence of tungsten reduction in a $\mathrm{H}_{2}$ atmosphere, which is aided by increased sintering temperature, during the low temperature sintering process.

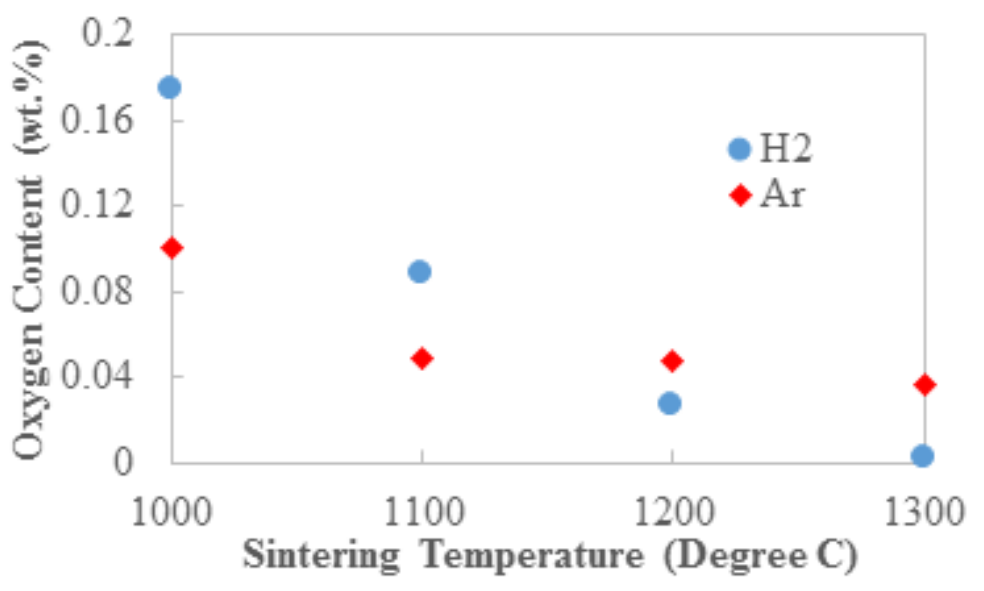

Figure 6 Effect of sintering temperature and atmosphere on the oxygen content of sintered nano-W powders.

Based on these results, throughout the entire sintering temperature range, an Ar atmosphere led to improved densification compared to a $\mathrm{H}_{2}$ atmosphere, and exhibited less grain growth. This was an 
unexpected result for sintering tungsten, although sintering atmosphere is well known to affect densification kinetics in a number of metallic systems [38]. Under identical processing conditions, the $\mathrm{Ar}$ atmosphere resulted in a higher relative density than occurred when sintering in a hydrogen atmosphere. And, at a comparable density, the Ar atmosphere resulted in smaller grain size, Fig. 5. Greater densification with less grain growth indicates a more bulk-transport controlled sintering process, while less densification with more grain growth likely relates to a surface-transport controlled mechanism [38]. Generally, tungsten sintering is performed in a reducing atmosphere, commonly pure hydrogen, which removes much of the oxygen in the powder compacts [39]. The reduction of tungsten oxides using $\mathrm{H}_{2}$ gas can be a complex process, where volatile $\mathrm{WO}_{2}(\mathrm{OH})_{2}$ is one of the intermediate products of reduction, and is formed by the reaction of $\mathrm{WO}_{2}$ and water vapor [40]. With the coexistence of oxides with hydrogen-water mixtures, tungsten experiences chemical vapor transport. Via the vapor phase, smaller grains evaporate and larger grains grow, which usually leads to a significant particle coarsening [39], but has no effect on bulk diffusion, which is required for densification.

Therefore, during the sintering process, a $\mathrm{H}_{2}$ atmosphere continually reduces tungsten oxides and generates $\mathrm{WO}_{2}(\mathrm{OH})_{2}$, which shifts the system toward a surface-transport controlled mechanism and leads to enhanced grain growth, while not necessarily facilitating the mechanisms for densification. An Ar atmosphere removes water vapor more effectively as a sweeping gas, and thereby limits the vapor transport mechanism that leads to grain coarsening. The net overall result is that sintering in $\mathrm{Ar}$ atmosphere leads to more densification and less grain growth than in $\mathrm{H}_{2}$ atmosphere. The effects of atmosphere have been studied by R. German on the sintering of the W-Fe-Ni heavy alloy system [41-43]. However, this is the first time that the effects of $\mathrm{H}_{2}$ and $\mathrm{Ar}$ atmosphere have been systematically analyzed for tungsten sintering. Similar effects have been reported previously on other systems, like $\mathrm{HCl}$ and air for $\mathrm{TiO}_{2}$ sintering [44] and $\mathrm{O}_{2}$ and $\mathrm{Ar}$ for $\mathrm{NiO}$ sintering [45].

\subsection{Effect of Reduction Temperature on Sintering of Nano-W Powders}

Due to the high activity of nano-sized powders, the HEPM processed nano-W powders tend to experience a certain level of oxidization during the milling, powder handling, and compaction processes. Sintering of tungsten is very sensitive to oxygen content, as a small amount of oxygen contamination can increase the activation energy for surface diffusion from $300 \mathrm{KJ} / \mathrm{mol}$ to nearly $400 \mathrm{KJ} / \mathrm{mol}$ [46]. Therefore, a reduction step using $\mathrm{H}_{2}$ is essential for the low temperature tungsten sintering process, and the reduction temperature was anticipated to have a significant effect on the densification of nano-W powders.

Figure 7 shows the evolution of sintered densities as a function of the reduction temperature for the HEPM milled nano-W powders. These samples were first reduced at 650 to $850^{\circ} \mathrm{C}$ in flowing $\mathrm{H}_{2}$ for $3 \mathrm{~h}$, followed by a two stage sintering sequence of $1050^{\circ} \mathrm{C}$ for $2 \mathrm{~h}$ and $1300^{\circ} \mathrm{C}$ for $1 \mathrm{~h}$ in flowing Ar. The relative density of sintered nano-W powders increases from $95.2 \%$ to $98.1 \%$ as the reduction temperature increases from 650 to $750{ }^{\circ} \mathrm{C}$, and then the density begins to decrease as the reduction temperature further increases to $850{ }^{\circ} \mathrm{C}$. Although all the samples had reached a relatively high densification, a $3 \%$ difference in density is very significant for sintering of nano-W powders. 


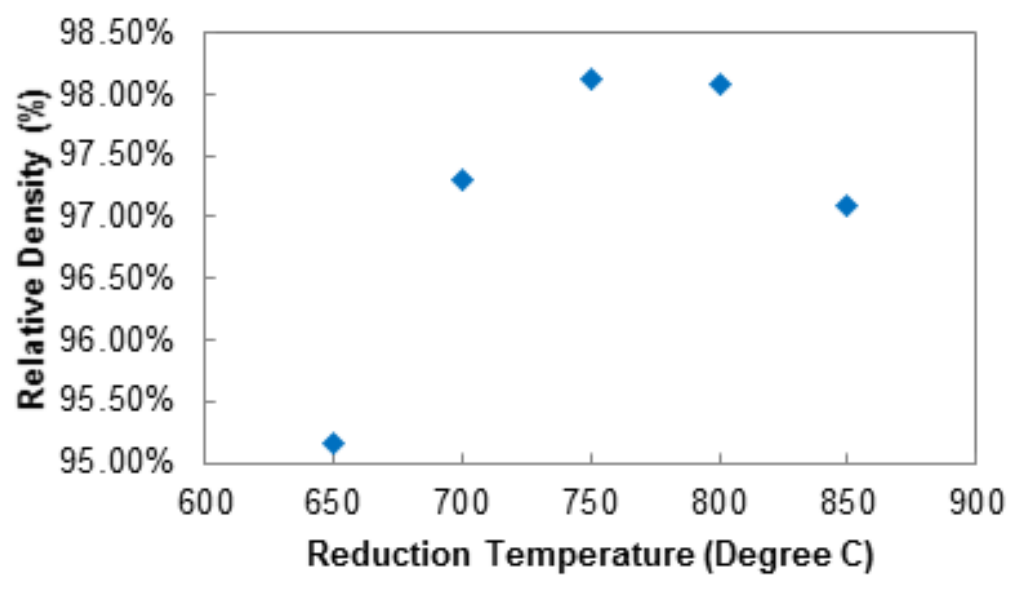

Figure 7 Effect of reduction temperature on the sintered relative density of nano-W powders.

In order to obtain a better understanding of the effects of reduction temperature, as-reduced tungsten samples were prepared by reducing samples at temperatures from 650 to $850{ }^{\circ} \mathrm{C}$ for $3 \mathrm{~h}$ and then directly cooling them in the furnace to room temperature. Figure 8 shows the changes in relative density of the as-reduced samples as a function of reduction temperature. From 650 to $800{ }^{\circ} \mathrm{C}$, the relative density increases gradually and shows less than a $2 \%$ increase in relative density. Although it represents less than a $2 \%$ increase in relative density, a more dramatic density increase occurs as the reduction temperature is further increased from 800 to $850{ }^{\circ} \mathrm{C}$. The Brunauer-Emmet-Teller (BET) method was utilized to calculate the surface area of as-reduced samples, and the results of these BET measurements are shown in Fig. 9. As the reduction temperature increases from 650 to $700{ }^{\circ} \mathrm{C}$, the BET surface area increases from 5.24 to $7.21 \mathrm{~m}^{2} / \mathrm{g}$. This is possibly caused by the newly exposed particle surfaces during the reduction, as tungsten and tungsten oxides have large differences in both crystal structure and density. Further increases in reduction temperature from 700 to $850{ }^{\circ} \mathrm{C}$ lead to a continuous decrease in the surface area, which indicates an increase in the particle size of W powders. This is clear evidence that grain coarsening of HEPM processed nano-W powders happens at a temperature of $500{ }^{\circ} \mathrm{C}$ below tungsten's recrystallization temperature and $2700{ }^{\circ} \mathrm{C}$ below its melting point. 


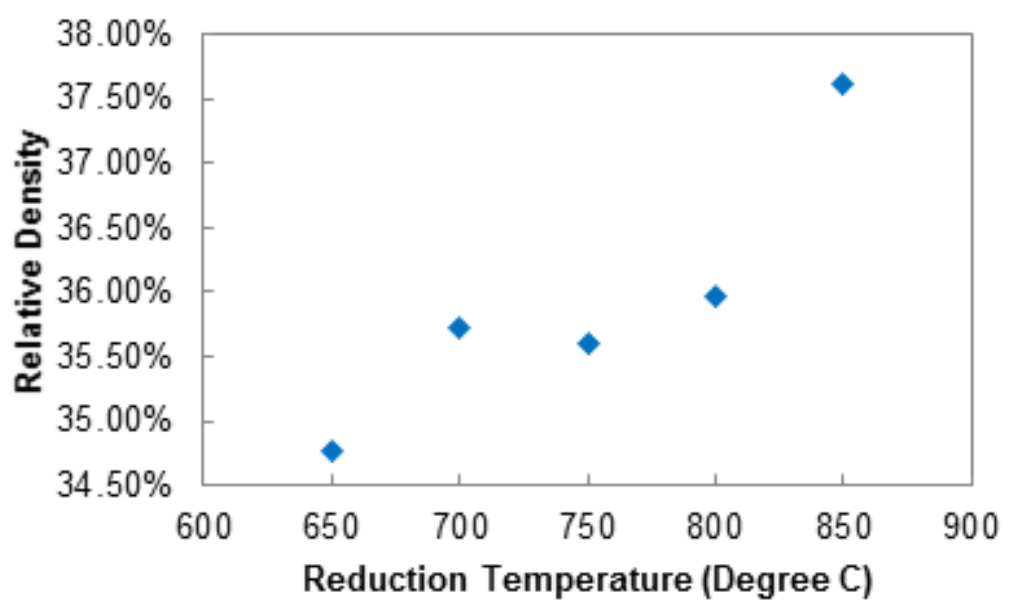

Figure 8 Effect of reduction temperature on the relative density of nano-W powders during the reduction process.

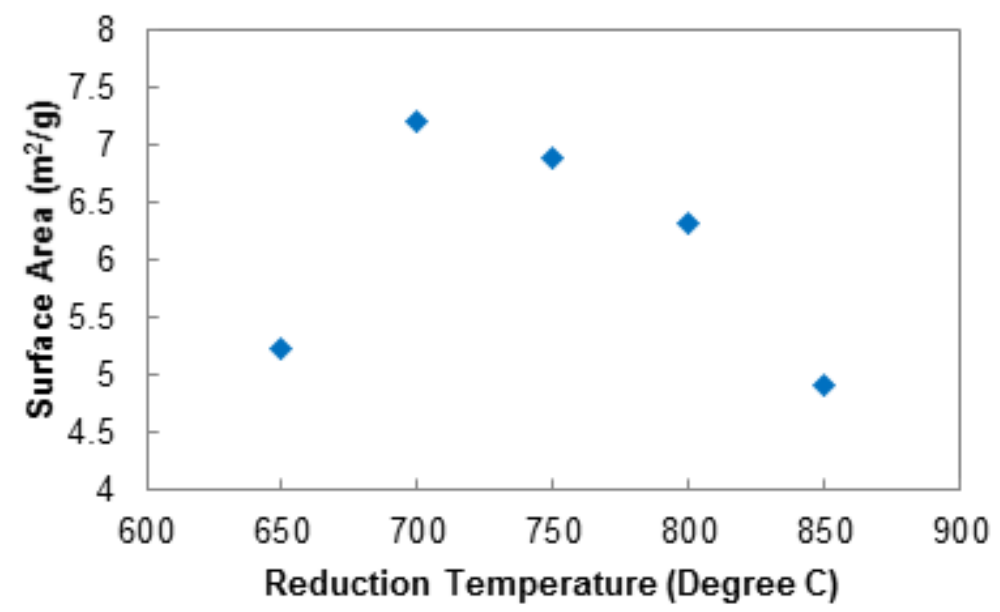

Figure 9 Effect of reduction temperature on the BET surface area of nano-W powders during the reduction process.

SEM images were taken on the as-reduced samples and Fig. 10 shows a comparison of compacted nano-W powders reduced at 700 and $850{ }^{\circ} \mathrm{C}$. Compared to the sample reduced at $700{ }^{\circ} \mathrm{C}$, the microstructure of the $850{ }^{\circ} \mathrm{C}$ reduced sample shows a smoother surface and formation of sinter bonds between the particles. The grain size of the $850{ }^{\circ} \mathrm{C}$ sample appears slightly larger than the $700{ }^{\circ} \mathrm{C}$ sample, which is consistent with what was observed in the BET results. Based on the solid-state sintering theory, powders may form sinter bonds between particles and experience coarsening without densification. This is usually due to surface diffusion or evaporation-condensation [38]. Tungsten is known to be active for surface diffusion at low temperature [46] and the potential chemical vapor transport by forming $\mathrm{WO}_{2}(\mathrm{OH})_{2}$ was discussed in the previous section. In this regard, a low temperature coarsening effect can be expected in the highly active nano-W powders during the reduction step. A considerable amount of surface area reduction and grain size increase occurred due to this low temperature coarsening, which consumes the surface energy that is responsible for densification. Therefore, a high temperature may 
improve the reduction kinetics of $W$ oxides, but the surface energy of powders consumed during this step will impede further densification during the sintering stage. For the HEPM processed nano-W powders with high surface activity a moderate reduction temperature, between 700 to $750{ }^{\circ} \mathrm{C}$, is more beneficial for obtaining near-full sintered density.

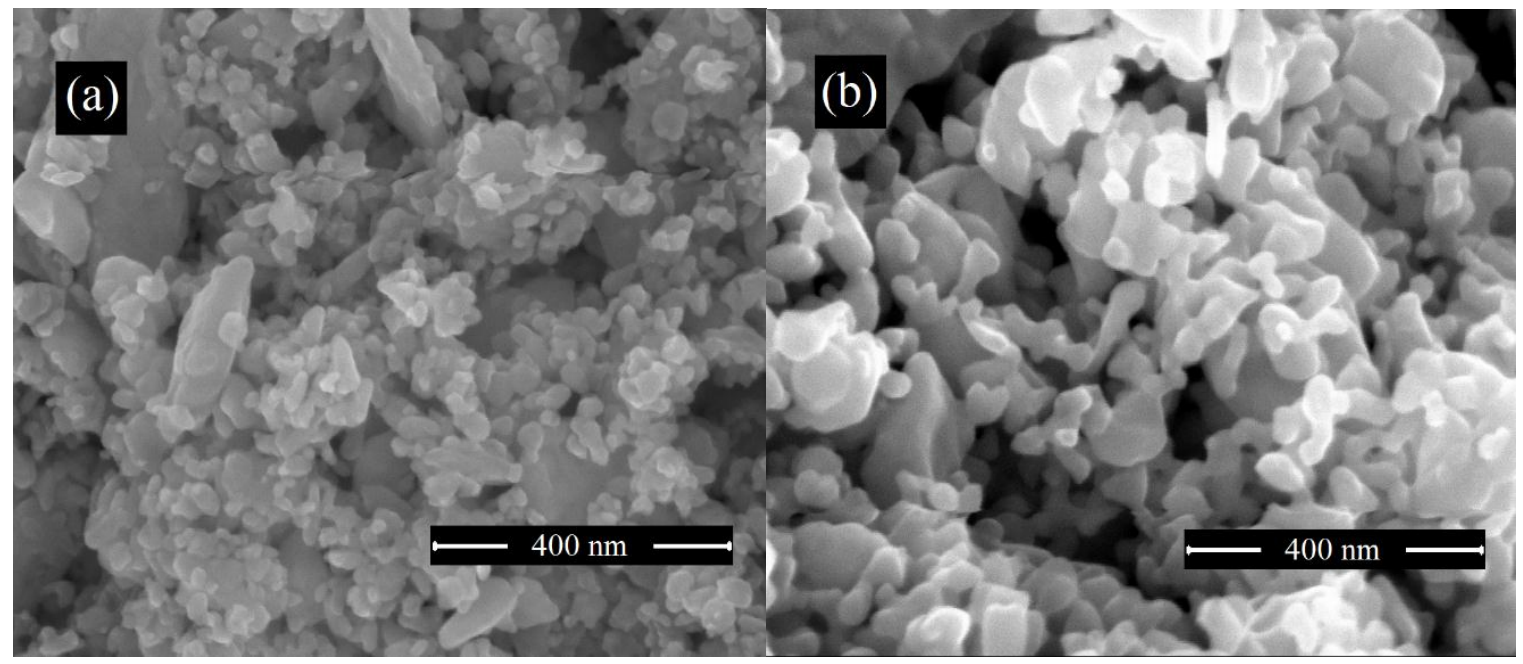

Figure 10 Comparison of microstructures of nano-W powders reduced at (a) $700^{\circ} \mathrm{C}$ and (b) $850{ }^{\circ} \mathrm{C}$.

\section{Conclusion}

Nano tungsten powders processed by high energy planetary milling had extremely high activity, and can reach near-full density by conventional pressureless sintering processes at temperatures as low as 1100 to $1300{ }^{\circ} \mathrm{C}$. Sintering nano-W powder in an Ar atmosphere promoted densification and limited grain growth, compared to samples of a comparable density sintered in a $\mathrm{H}_{2}$ atmosphere. A reduction step is necessary for sintering the high surface activity nano-W powder, and the selection of reduction temperature was found to affect both the sintered density and grain size.

\section{Acknowledgements}

The Authors wish to thank the U.S. Department of Energy (DOE) (DESC0008673), Office of Science, Fusion Materials Program and the U.S. Department of Defense (DOD) SBIR program for financial support. The authors also would like to thank Mr. Brady Butler from the Army Research Laboratory for many valuable discussions.

\section{References}

[1] M. Rieth, S.L. Dudarevb, S. M. Gonzalez de Vicente, et al., Recent progress in research on tungsten materials for nuclear fusion application in Europe, J. Nucl. Mater. 432 (2013) 482-500.

[2] R. Causey, K. Wilson, T. Venhaus, W. R. Wampler, Tritium retention in tungsten exposed to intense fluxes of $100 \mathrm{eV}$ tritons, J. Nucl. Mater. 266-269 (1999) 467-471.

[3] G. Federici, A. Zhitlukin, N. Arkhipov, R. Giniyatulin, N. Klimov, I. Landman, V. Podkovyrov, V. Safronov, A. Loarte, M. Merola, Effects of ELMs and disruptions on ITER divertor armour materials, J. Nucl. Mater. 337-339 (2005) 684-690. 
[4] H. Bolt, V. Barabash, W. Krauss, J. Linke, R. Neu, S. Suzuki, N. Yoshida, Materials for the plasma-facing components in future fusion devices, J. Nucl. Mater. 329-333 (2004) 66-73.

[5] J. W. Davisa, V. R. Barabashb, A. Makhankovc, L. Plochld, L. T. Slatterya, Assessment of tungsten for use in the ITER plasma facing components, J. Nucl. Mater. 258 (1998) 308-312.

[6] G. Janeschitz, Plasma-wall interaction issues in ITER, J. Nucl. Mater. 290-293 (2001) 1-11.

[7] P. Norajitra, L.V. Boccaccini, A. Gervash, R. Giniyatulin, N. Holstein, T. Ihli, G. Janeschitz, W. Krauss, R. Kruessmann, V. Kuznetsov, A. Makhankov, I. Mazul, A. Moeslang, I. Ovchinnikov, M. Rieth, B. Zeep, Development of a helium-cooled divertor: material choice and technological studies, J. Nucl. Mater. 367-370 (2007) 1416-1421.

[8] H. Kurishita, S. Kobayashi, K. Nakai, T. Ogawa, A. Hasegawa, K. Abe, H. Arakawa, S. Matsuo, T. Takida, K. Takebe, M. Kawai, N. Yoshida, Development of ultra-fine grained W-(0.25-0.8)wt\%TiC and its superior resistance to neutron and $3 \mathrm{MeV}$ He-ion irradiations, J. Nucl. Mater. 377 (2008) 34-40.

[9] H. Kurishita, Y. Amano, S. Kobayashi, K. Nakai, H. Arakawa, Y. Hiraoka, T. Takida, K. Takebe, H. Matsui, Development of ultra-fine grained $\mathrm{W}-\mathrm{TiC}$ and their mechanical properties for fusion applications, J. Nucl. Mater. 367 (2007) 1453-1457.

[10] R. E. Nygren, R. Raffray, D. Whyte, et al., Making tungsten work, J. Nucl. Mater. 417 (2011) 451-456.

[11] Y. Kitsunai, H. Kurishita, H. Kayano, Y. Hiraoka, T. Igarashi, T. Takida, Microstructure and impact properties of ultra-fine grained tungsten alloys dispersed with TiC, J. Nucl. Mater 271-272 (1999) 423-428.

[12] P. L. Sun, E. K. Cerreta, J. F. Bingert, G. T. Gray III, M. F. Hundley, Enhanced tensile ductility through boundary structure engineering in ultrafine-grained aluminum, Mater. Sci. Eng. A 464 (2007) 343350.

[13] G. M. Cheng, W. W. Jian, W. Z. Xu, H. Yuan, P. C. Millett, Y. T. Zhu, Grain Size Effect on Deformation Mechanisms of Nanocrystalline bcc Metals, Math. Res. Lett. 1 (2013) 26-31.

[14] M. Samras, P. M. Derlet, H. Van Swygenhoven, M. Victoria, Computer Simulation of Displacement Cascades in Nanocrystalline Ni, Phys. Rev. Lett. 88 (2002) 125505.

[15] X.M. Bai, A.F. Voter, R.G. Hoagland, M. Nastasi, B.P. Uberuaga, Efficient Annealing of Radiation Damage Near Grain Boundaries via Interstitial Emission, Science 327 (2010) 1631-1634.

[16] L. J. Kevskes, K. C. Cho, R. J. Dowding, B. E. Schuster, R. Z. Valiev, Q. Wei, Grain size engineering of bcc refractory metals: top-down and bottom-up application to tungsten, Mater. Sci. Eng. 467 (2007) 33-34.

[17] R.Z. Valiev, R.K. Islamgaliev, I.V. Alexandrov, Bulk nanostructured materials from severe plastic deformation, Prog. Mater. Sci. 45 (2000) 103-189.

[18] R.Z. Valiev, T.G. Langdon, Principles of equal-channel angular pressing as a processing tool for grain refinement, Prog. Mater. Sci. 51 (2006) 881-981. 
[19] Y. Saito, H. Utsunomiya, T.Y. Tsui, T. Sakai, Novel ultra-high straining process for bulk materials development of the accumulative roll-bonding (arb) process, Acta Mater. 47 (1999) 579-583.

[20] A.P. Zhilyaev, G.V. Nurislamova, B.-K. Kim, M.D. Baro, J.A. Szpunar, T.G. Langdon, Experimental parameters influencing grain refinement and microstructural evolution during high-pressure torsion, Acta Mater. 51 (2003) 753-765.

[21] Y. Zhang, A.V. Ganeev, J.T. Wang, J.Q. Liu, I.V. Alexandrov, Observations on the ductile-to-brittle transition in ultrafine-grained tungsten of commercial purity, Mater. Sci. Eng. A 503 (2009) 37-40.

[22] Q. Wei, H. T. Zhang, B. E. Schuster, et al., Microstructure and mechanical properties of super-strong nanocrystalline tungsten processed by high-pressure torsion, Acta Mater. 54 (2006) 4079-4089.

[23] M.A. Monge, M. A. Auger, T. Leguey, Y. Ortega, L.Bolzoni, E. Gordo, R. Pareja, Characterization of novel W alloys produced by HIP, J. Nucl. Mater. 386-388 (2009) 613-617.

[24] V. Piotter, B. Zeep, P. Norajitra, R. Ruprecht, A. von der Weth, J. Hausselt, Development of a powder metallurgy process for tungsten components, Fusion Eng. Des. 83 (2008) 1517-1520.

[25] M. A. Yar, S. Wahlberg, H. Bergqvist, H. G. Salem, M. Johnsson, M. Muhammed, Spark plasma sintering of tungsten-yttrium oxide composites from chemically synthesized nanopowders and microstructural characterization, J. Nucl. Mater. 412 (2011) 227-232.

[26] G. Prabhu, A. Chakraborty, B. Sarma, Microwave sintering of tungsten J. Refract. Met. Hard Mater. 27 (2009) 545-548.

[27] ] J.D. Paramore, H. Zhang, X. Wang, et al., Production of nanocrystalline tungsten using ultra-highpressure rapid hot consolidation (UPRC), Proceedings of the 2007 International Conference on Powder Metallurgy \& Particulate Materials, compiled by Engquist J and Murphy TF, Metal Powder Industries Federation, Princeton, NJ, 8 (2007) 1-9.

[28] Y. Kim, K.H. Lee, E.P. Kim, D.I. Cheong, S.H. Hong, Fabrication of high temperature oxides dispersion strengthened tungsten composites by spark plasma sintering process Int. J. Refract. Met. Hard Mater. 27 (2009) 842-846.

[29] S. Wahlberg, M.A. Yar, M.O. Abuelnaga, H.G. Salem, M. Johnsson, M. Muhammed, Fabrication of nanostructured $\mathrm{W}-\mathrm{Y}_{2} \mathrm{O}_{3}$ materials by chemical methods, J. Mater. Chem. 22 (2012) 12622-12628.

[30] R. Liu, Z. M. Xie, Q. F. Fang, T. Zhang, X. P. Wang, T. Hao, C. S. Liu, Y. Dai, Nanostructured yttria dispersion-strengthened tungsten synthesized by sol-gel method, J. Alloys Compd. 657 (2016) 73-80.

[31] R.M. German, E. Olevsky, Mapping the compaction and sintering response of tungsten-based materials into the nanoscale range, Int. J. Refract. Met. Hard Mater. 23 (2005) 294-300.

[32] J. L. Johnson, Progress in processing nanoscale refractory and hard metal. Proceedings of the 2008 Tungsten, Refractory \& Hard Materials VII, Washington, P.05.57-71.

[33] H. Wang, Z.Z. Fang, Sinter-ability of nanocrystalline tungsten powder, Int. J. Refract. Met. Hard Mater. 28 (2010) 312-316. 
[34] X. Wang, Z. Z. Fang, M. Koopman, The relationship between the green density and as-sintered density of nano-tungsten compacts, Int. J. Refract. Met. Hard Mater. 53 (2015) 134-138.

[35] B. G. Butler, J. Lu, Z. Z. Fang, R. K. Rajamani, Production and characteristics of nanocrystalline tungsten carbide powder using a high energy dual-drive planetary mill. Int. J Powder Metall. 43 (2007) 35-43.

[36] G. K. Williamson, W. H. Hall, X-ray line broadening from filled aluminum and wolfram. Acta Metall. 1 (1953) 22-31.

[37] S. W. H. Yih, C. T. Wang, Tungsten, 1979 Plenum Press, New York.

[38] R. M. Germam, 1996. Sintering Theory and Practice. Wiley, New York.

[39] E. Lassner, W. D. Schubert, Tungsten - Properties, chemistry, technology of the element, alloys and chemical compounds, Kluwer Academic / Plenum Publisher, New York (1999).

[40] O. Glemser, H. Ackermann, Gasförmige Hydroxide. VI. Ergänzende Untersuchungen über gasförmiges $\mathrm{WO}_{2}(\mathrm{OH})_{2}$, Z. Anorg. Allg. Chem. 325 (1963), 281-286.

[41] A. Bose, R. German, Sintering Atmosphere Effects on Tensile Properties of Heavy Alloys, Metall. Mater. Trans. 19 (1988) 2467-2476.

[42] R. German, A. Bose, S. Mani, Sintering Time and Atmospheres Influences on the Microstructure and Mechanical Properties of Tungsten Heavy Alloys, Metall. Mater. Trans. 23 (1992) 211-219.

[43] R. German, Sintering Atmosphere Effects on the Ductility of W-Ni-Fe Heavy Metals, Metall. Mater. Trans. 15 (1984) 747-754.

[44] M. J. Readey, D. W. Readey, Sintering of $\mathrm{TiO}_{2}$ in $\mathrm{HCl}$ Atmospheres, J. Amer. Ceram. Soc. 70 (1987) C385-C361.

[45] S. B. Boskovic, M. M. Ristic, Sintering of Nonstoichiometric Nickel Oxide, Soviet Powder Met. Metal. Ceram. 11 (1972) 755-759.

[46] M. Pichaud, M. Drechsler, A Field Emission Measurement of the Influence of Adsorption on Surface Self-Diffusion, Surface Sci. 32 (1972) 341-348. 